\title{
EFFECTS OF CHEMICAL COMPOSITIONS OF CHITOSAN-BASED HYDROGEL ON PROPERTIES AND COLLAGEN RELEASE
}

\author{
Patiparn Boonruam and Piyachat Wattanachai* \\ Department of Chemical Engineering, Faculty of Engineering, Burapha University, Chonburi, Thailand, \\ Tel: +66 805674204, e-mail: piyachat.a@eng.buu.ac.th
}

Received Date: December 8, 2019; Revised Date: August 31, 2020; Acceptance Date: December 2, 2020

\begin{abstract}
Chitosan-based hydrogels have drawn attention from a wide range of applications including drug delivery, heavy metal removal, and wound dressing. This is due to its biocompatibility, biodegradability, and responsiveness. Physical crosslinking is an easy and eco-friendly way to form hydrogels and the degree of crosslinking influences their mechanical and mass-transport properties. In this research, polyvinyl alcohol (PVA) was used as a co-hydrogel base polymer along with chitosan, where it was found that an increase in the PVA content by $1 \% \mathrm{w} / \mathrm{v}$ improved the tensile strength of the hydrogel film by $75 \%$. An increase in glycerol which is a plasticizer increased hydrogel elasticity but lowered the tensile strength of the film. When the surfactant, Polysorbate 80 (PS80), was added at a concentration of $0.5 \% \mathrm{w} / \mathrm{v}$, the tensile strength improved between $70-150 \%$. The hydrogel film with a high degree of crosslinking possessed good mechanical properties; however, contained less amounts of voids resulting in less water absorption. The results illustrated that percent swelling as high as $650 \%$ could be obtained. Surprisingly, although the percent swelling varied according to the mechanical properties of the films, the absorption of collagen solution was indistinguishable and remained at 30\% absorption for all the film compositions studied. Nevertheless, collagen release correlated with the mechanical properties and percent swelling of the hydrogel films, where high percent swelling films released collagen faster. As they are physically incorporated, there are weak interactions between collagen and hydrogels, resulting in considerably fast collagen release which was completed within 5-6 hrs.
\end{abstract}

Keywords: Biodegradable, Chitosan, Collagen, Hydrogel, PVA

\section{Introduction}

Hydrogels are polymeric materials bonded together either physically or chemically to form a three dimensional cross-linked network structure and hence can absorb and retain considerable amounts of water or biological fluids inside its structure. Polymers used to form hydrogel must be hydrophilic polymers and their ability to absorb water depend on the density of the hydrophilic groups present on the polymers. Various hydrophilic polymers used for hydrogels include polyvinyl alcohol (PVA), polyethylene glycol (PEG), polyurethane (PU), poly (methacrylic acid) (PMMA), and polyacrylamide (PAM) [1,2]. There are a large number of hydrogel applications including drug delivery, heavy metal removal, wound dressing, contact lenses, sensors, energy storage, and tissue engineering [35]. Towards the green technology, recent research has focused on bio-based hydrogels, such as chitosan, cellulose, starch, alginate, and gelatin, due to their biocompatibility, biodegradability, non-toxicity, and responsiveness [3,6-8].

Chitosan is a linear polysaccharide and can be extracted from natural resources such as the hard-outer skeleton of shellfish, including crabs, lobsters, and shrimp. Chitosan is a copolymer of 2-glucosamine and $\mathrm{N}$-acetyl-2-glucosamine units and has been used in a 
wide range of applications including water treatment, food packaging, tissue engineering, and sensors. Asides from its biocompatibility and biodegradability, chitosan has other advantages including antioxidant and antibacterial properties. However, chitosan suffers from dissolution in highly acidic solution, low surface area, high cost and poor thermal and mechanical properties, which restrict its applications. PVA is a semi-crystalline, watersoluble synthetic polymer with excellent chemical resistance, high hydrophilic properties, good mechanical properties, excellent biocompatibility and good film forming properties. As both chitosan and PVA contain $\mathrm{OH}$ groups, both polymers showed good compatibility and hence recently PVA has been incorporated into chitosan-based hydrogels to improve its matrix properties. The PVA/chitosan films showed remarkable UV resistance and PVA provides the elasticity to the chitosan films $[8,9]$. The structure of chitosan/PVA composite and hence the swelling behavior could be altered by its nanoparticles content. With low amounts of lignin nanoparticles, the pore sizes within hydrogels enlarged and hence absorbed more water [10]. Conversely, an increase in lignin nanoparticle amount can be detrimental to its water absorption because of the hydrophobic nature of lignin. Nevertheless, it was reported that hydrogels incorporated with lignin exhibits excellent antioxidant activity, impact resistance, and tensile properties [5]. Silver nanoparticles, on the other hand, lowered the swelling capacity of the chitosan/PVA hydrogels due to the binding of silver nanoparticles with electrons from the oxygen and nitrogen atoms in the hydroxyl and amine groups in the chitosan/PVA chains [9]. Addition of gelatin in the chitosan/PVA hydrogel was found to compensate for the chitosan's crosslink density, which was lost during the Gamma radiation polymerization and resulted in an improvement of the tensile strength [11]. However, as the tensile properties improved, the swelling of the film decreased and a longer time was required to coagulate the blood from wounds. Similarly, cellulose nanoparticles were observed to be a good reinforcing material for the alginate/PVA and chitosan/PVA hydrogels [12]. However, their conclusion that the nanoparticles were located inside the polymeric chains network, reducing the space between the chains and causing a greater swelling, was not in agreement with others. Liu et al. fabricated chitosan/PVA hydrogels in a form of nanofiber mats and it was found that with different amount of ethylene glycol diglycidyl ether (EGDE) cross-linker, the diameters of the nanofibers were slightly different [13]. The swelling of these nanofibers showed similar trend as other normal form of hydrogels where higher crosslink density resulted in lower swelling or water absorption. Although it was found that the coconut fiber cellulose reduced the PVA hydrogel porosity, the ability of the hydrogels to entrain and release methylene blue were enhanced up to $20 \%$ wt. cellulose in which showed the highest degree of swelling [14]. In addition, the release was found to be very rapid within 5-10 min. The ability of drug loading into the hydrogels depends on the drug's polarity. Since hydrogel is hydrophilic, 5-Fluorouracil can be loaded into xylan- $\beta$,cyclodextrin hydrogel perfectly well while only $20 \%$ wt. of curcumin can be loaded [15]. Even though the entrapment of the drugs in different hydrogels were similar, the accumulated release of the drugs depended greatly on its swelling properties. The hydrogel with the highest swelling ratio showed the highest drug release. It was also observed that drug release is mainly influenced by the charge repulsion between the hydrogel and the drug in addition to the media exchange between the interior and the exterior of the hydrogel or $\mathrm{pH}$ of the media [16-18].

Collagen is the most abundant protein in our body, making up approximately $30 \%$ of the proteins within the body and $70 \%$ of the proteins within human skin. Its role is to support structures and anchor cells to each other and hence it is very important for wound healing. It can be extracted from different parts of animals including fish scales [19]. It has been reported that the addition of collagen in chitosan hydrogels can enhance fibroblast cell growth which improves cell adhesion needed for wound dressings [20]. Osteoblast culture 
could also be encouraged with collagen-incorporated chitosan hydrogels since more mineralization are attained compared to pure chitosan hydrogels [21].

Although chemically cross-linked hydrogels seem to have superior mechanical properties, physical crosslinking is an easy and eco-friendly way to form hydrogels. The degree of crosslinking influences hydrogel properties such as mechanical and mass-transport properties. The objective of this study was to investigate the effects of chemical compositions on the physical and mechanical properties of the chitosan/PVA hydrogel, in particular the collagen absorption and release (desorption).

\section{Experimental}

Table 1. Chemical Compositions (in \% w/v of chitosan solution) of Hydrogel Films

\begin{tabular}{ccccc|ccccc} 
Sample & PVA & Glycerol & PS80 & Ethanol & Sample & PVA & Glycerol & PS80 & Ethanol \\
\hline 1 & 1 & 2.5 & 0 & 0 & 13 & 1 & 5.0 & 0.5 & 0 \\
\hline 2 & 2 & 2.5 & 0 & 5 & 14 & 2 & 5.0 & 1 & 0 \\
\hline 3 & 3 & 2.5 & 0 & 10 & 15 & 3 & 5.0 & 0.25 & 0 \\
\hline 4 & 1 & 5.0 & 0 & 5 & 16 & 1 & 7.5 & 1 & 0 \\
\hline 5 & 2 & 5.0 & 0 & 10 & 17 & 2 & 7.5 & 0.25 & 0 \\
\hline 6 & 3 & 5.0 & 0 & 0 & 18 & 3 & 7.5 & 0.5 & 0 \\
\hline 7 & 1 & 7.5 & 0 & 10 & 19 & 2 & 2.5 & 0 & 0 \\
\hline 8 & 2 & 7.5 & 0 & 0 & 20 & 2 & 2.5 & 0.5 & 0 \\
\hline 9 & 3 & 7.5 & 0 & 5 & 21 & 3 & 2.5 & 0.5 & 0 \\
\hline 10 & 1 & 2.5 & 0.25 & 0 & 22 & 3 & 5.0 & 0 & 0 \\
\hline 11 & 2 & 2.5 & 0.5 & 0 & 23 & 2 & 5.0 & 0.5 & 0 \\
\hline 12 & 3 & 2.5 & 1 & 0 & 24 & 3 & 5.0 & 0.5 & 0 \\
\hline
\end{tabular}

\section{Materials}

Chitosan extracted from prawn shells was obtained in powder form with a molecular weight of 2,100 kDa from Marine Bio Resource Co., Ltd., Thailand. Polyvinyl alcohol (PVA), also in powder form, was purchased from Japan Vam \& Poval Co., Ltd., Japan and glycolic acid (AHA) was obtained from Thornhill Advanced Research Inc., Canada. Polysorbate 80 (PS80) used as a surfactant was received from Sino-Japan chemical Co., Ltd., China. A plasticizer, 99.5\% analytical reagent (AR) grade glycerol solution, was obtained from GRëC, New Zealand. Cosmetic grade collagen was obtained from Science Diagnostic Materials Co., Ltd., Thailand. 


\section{Hydrogel Film Preparation}

The effects of 3 chemical compositions, i.e. glycerol, PVA, and PS80, in the hydrogel solutions were investigated and a fractional factorial design was used to design the experiments as shown in Table 1 . Solutions of $150 \mathrm{ml}$ volume with fixed concentrations of chitosan and glycolic acid at 2 and $1 \% \mathrm{w} / \mathrm{v}$, respectively, was prepared by mixing for $1 \mathrm{hr}$ at a room temperature $\left(25^{\circ} \mathrm{C}\right)$ as chitosan is soluble only in dilute acidic solution. PVA solution $(75 \mathrm{ml})$ was prepared according to the desired concentration ranging from 1-3\% w/v of chitosan solution by dissolving PVA powder in distilled water at $95^{\circ} \mathrm{C}$ for $30 \mathrm{~min}$. The two mixtures (chitosan and PVA) were combined and glycerol, ethanol, and PS 80 were included at the desired compositions. The mixture was then stirred at $70^{\circ} \mathrm{C}$ for another hour prior to centrifugation at 4,000 rpm for $10 \mathrm{~min}$ in order to remove air bubbles in the solution. One third of the solution was poured into $100 \mathrm{~mm}$ petri dish and dried in an oven at $60^{\circ} \mathrm{C}$ for 24 hrs to form one hydrogel film. Three hydrogel films were obtained from each solution. Figure 1 illustrates the experimental flow diagram. In addition, the effects of hydrogel film thickness on the properties of the film were also carried out. The films were formed by using two different quantities of hydrogel solution, i.e., 20 and $35 \mathrm{~g}$, for the film casting.

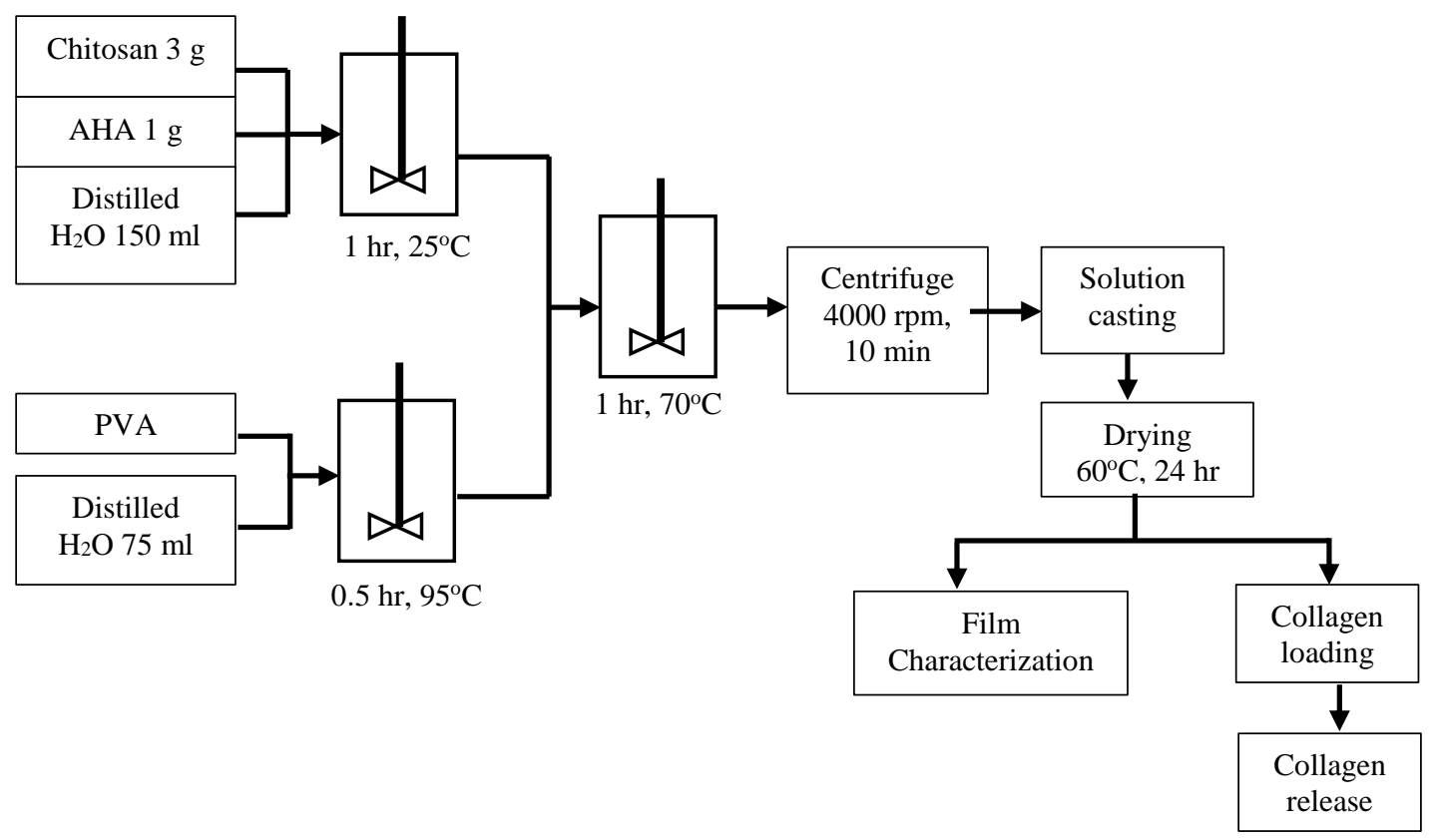

Figure 1. Hydrogel film preparation flow diagram

\section{Characterization}

Three hydrogel films of each sample were characterized and the average results as well as standard deviations were evaluated. To investigate a drying time for the film, the films were weighed every 6 hrs during oven drying. Film thickness and color measurements were carried out on at least five positions for each film using a thickness gauge and Ultrascan XE HunterLab spectrophotometer for color, respectively, prior to undertaking other destructive tests. The center of each film was then cut into 4 specimens; 1 of the size of $1 \times 5 \mathrm{~cm}$ for the tensile test and 3 of the size of $1 \times 2 \mathrm{~cm}$ for the water and collagen absorption tests. For the tensile test, the specimen was soaked in a $15 \% \mathrm{w} / \mathrm{v}$ collagen solution for $12 \mathrm{hrs}$ prior to the test. The test was performed in a tension mode using a TA.XT plusC Texture Analyzers, Stable Micro Systems Ltd., UK, with a test speed of $3 \mathrm{~mm} / \mathrm{s}$. For the water absorption test, one of the $1 \times 2 \mathrm{~cm}$ specimens was weighed and then soaked in a $10 \mathrm{ml}$ distilled water at $25^{\circ} \mathrm{C}$. 
It was carefully taken out of the water momentarily for weight measurement at 3,6, 9, 12, and $24 \mathrm{hrs}$. The water absorption can be represented in terms of the swelling ratio which is determined by the following equation.

$$
\text { Swelling ratio }(\%)=\frac{W_{s}-W_{d}}{W_{d}} \times 100
$$

where $\mathrm{W}_{\mathrm{s}}$ is the weight of the film at time $\mathrm{t}$ and $\mathrm{W}_{\mathrm{d}}$ is the dry weight before soaking in the water.

The collagen absorption and release were tested using the other two $1 \times 2 \mathrm{~cm}$ specimens. Two concentrations of the collagen solution were studied, i.e. 15 and $30 \% \mathrm{w} / \mathrm{v}$. The film was weighed before soaking in the $10 \mathrm{ml}$ collagen solution at $25^{\circ} \mathrm{C}$ for $24 \mathrm{hrs}$. After $24 \mathrm{hrs}$ of soaking, the film was removed from the solution and was oven dried at $37^{\circ} \mathrm{C}$ for $24 \mathrm{hrs}$. The remaining concentration of collagen in the soaking solution was determined using a CARY 1E Varian UV-Vis Spectrophotometer at the wavelength of $274 \mathrm{~nm}$ to determine the collagen absorbed by the film. To study collagen release, the oven dried hydrogel film from the absorption experiment was soaked in a $10 \mathrm{ml}$ phosphate buffer saline (PBS) at $37^{\circ} \mathrm{C}$ and the $\mathrm{pH}$ of 5.5 which represents the $\mathrm{pH}$ of human skin. Approximately 1 $\mathrm{ml}$ of PBS was removed and used to determine the release of collagen using the UV-Vis Spectrophotometer at the wavelength of $274 \mathrm{~nm}$ after soaking periods of $0.5,1,3,6$ and 12 hrs. Each time that the $1 \mathrm{ml}$ of PBS was taken out, $1 \mathrm{ml}$ of fresh PBS was added to maintain the $10 \mathrm{ml}$ soaking solution. The standard curve for collagen concentrations was obtained by dissolving the collagen in distilled water at various concentrations.

\section{Results and Discussions}

\section{Drying Time}

To investigate the drying time and the factors affecting the drying time of the hydrogel films, preliminary tests of samples 1-9 were carried out. The criteria used to verify whether the film had been sufficiently dried was that the weight-lost to dry-weight ratio was less than 0.1 . The drying results, not shown here, revealed rapid drying occurred during the first $12 \mathrm{hrs}$ and the weight lost with time had a linear relationship. This is attributed to the water molecules being far apart and therefore easy to move and evaporate. Most of the films were dried (weight-lost to dry weight ratio < 0.1 ) after 24 hrs except for samples 4 , 5 , and 6 , and hence the drying time of 24 hrs was subsequently used for further experiments. Analysis of variance (ANOVA) was employed to assess the significance of the main chemical compositions i.e. glycerol, PVA, and ethanol, on the drying rate. The results of the experimental data analysis using Minitab is displayed in Figure 2. At a significance level of $\alpha=0.05$, it was shown that glycerol and PVA have a strong influence (P-value $=0.000)$ while ethanol does not have any significant effect on the drying of the hydrogel films $(\mathrm{P}$-value $=0.903)$. This might be because ethanol has considerably higher vapor pressure than that of other chemicals including water and therefore evaporate quickly at the initial stage and did not affect the drying of the film. In addition, PVA is only slightly soluble in ethanol. As a result, ethanol was not added into subsequent samples (samples 10-24). At low PVA content of $1 \% \mathrm{w} / \mathrm{v}$ and glycerol content of $2.5 \% \mathrm{w} / \mathrm{v}$, the solution had lower viscosity and concentration, resulting in higher vapor pressure and was therefore easier to evaporate with a drying time of around 18-20 hrs. As the amount of PVA or glycerol increased the drying time also increased up to more than $28 \mathrm{hrs}$ due to the interaction between water and solute and steric hindrance. At high PVA content of $3 \% \mathrm{w} / \mathrm{v}$ and glycerol content of $7.5 \% \mathrm{w} / \mathrm{v}$, the amount of distilled water in the solution was less and hence the evaporation rate increased again. 


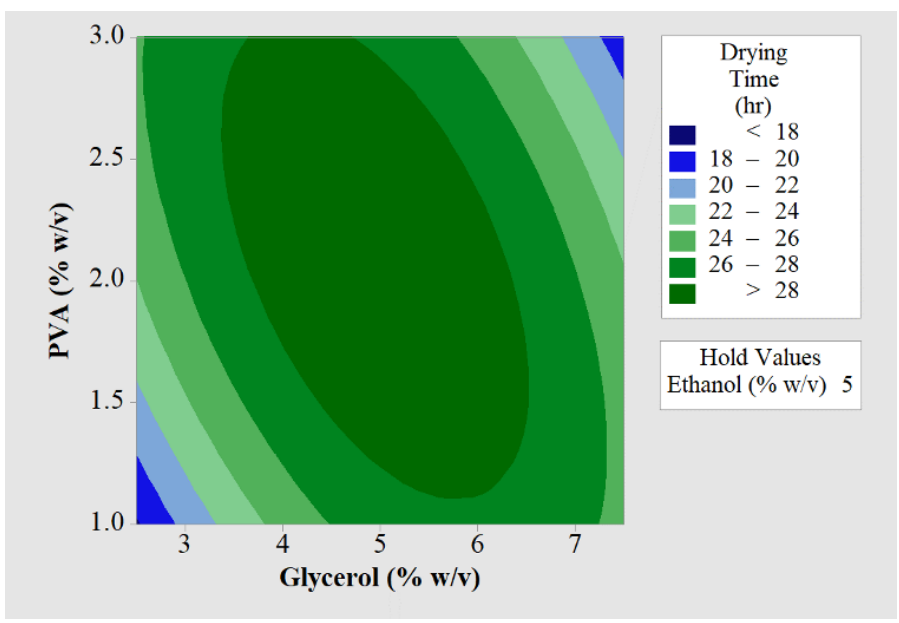

Figure 2. Contour plot of glycerol and PVA concentrations with drying time at the ethanol concentration of $5 \% \mathrm{w} / \mathrm{v}$

\section{Physical Properties}

Due to the moderately high viscosity of the hydrogel solution, the hydrogel films were slightly thicker in the middle which was the pouring position for film casting. The film thickness was linearly increased with the solid contents in the solution (chitosan, glycolic acid, PVA, and PS80) as well as the quantity of solution used to form the films as illustrated in Figure 3. As the amount of the solution increased from 20 to $35 \mathrm{~g}$ (1.8 times), the film thickness of all the samples also increased by around 1.8 times. With the $20 \mathrm{~g}$ solution casting, the film thickness measured was in the range of 9-18 $\mathrm{mm}$ and approximately of 16$32 \mathrm{~mm}$ for the $35 \mathrm{~g}$ solution casting. The differences in film thickness were found to influence the mechanical properties and percent swelling of the film which is discussed in the next section.

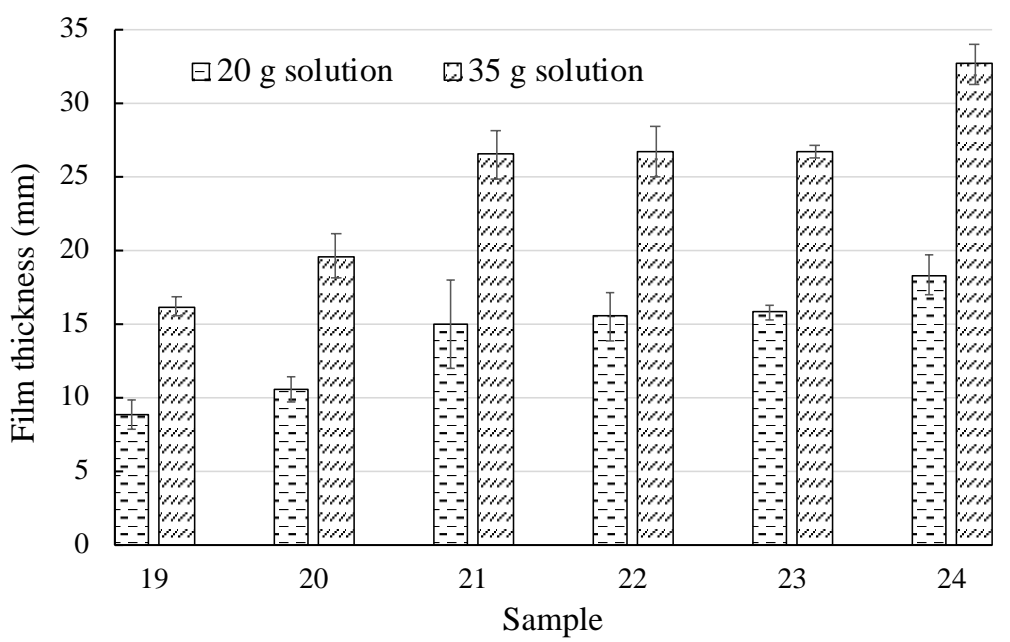

Figure 3. Hydrogel film thickness of $20-\mathrm{g}$ and $35-\mathrm{g}$ solution used for film casting

Figure 4 shows the appearance of the hydrogel films for Samples 10-24. The image shows that the films were yellowish in color and there is no visual difference to distinguish between the varying chemical compositions. There were no differences in $a, b$, $\mathrm{L}$ values measured using the spectrophotometer for color except $\%$ haze which was measured between $0-15 \%$ as shown in Figure 5. As the amount of casting solution increased from 20 
to $35 \mathrm{~g}$, the \%haze also increased due to the higher amount of solid contents. Although the films with different PVA and PS80 contents possess different opacity, ANOVA testing at a significance level of $\alpha=0.05$ confirmed that only glycerol had a significant effect on the $\%$ haze with a P-value of 0.017 . Nevertheless, the differences in these physical properties did not influence abilities for collagen absorption and release which is discussed in the later sections.

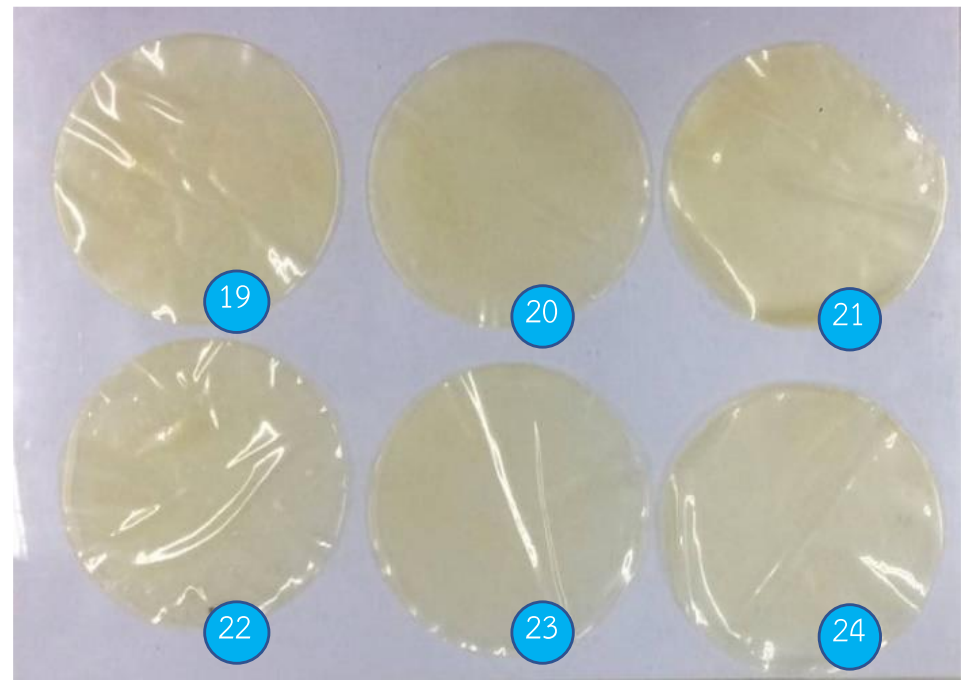

Figure 4. Appearances of Samples 19-24 hydrogel films

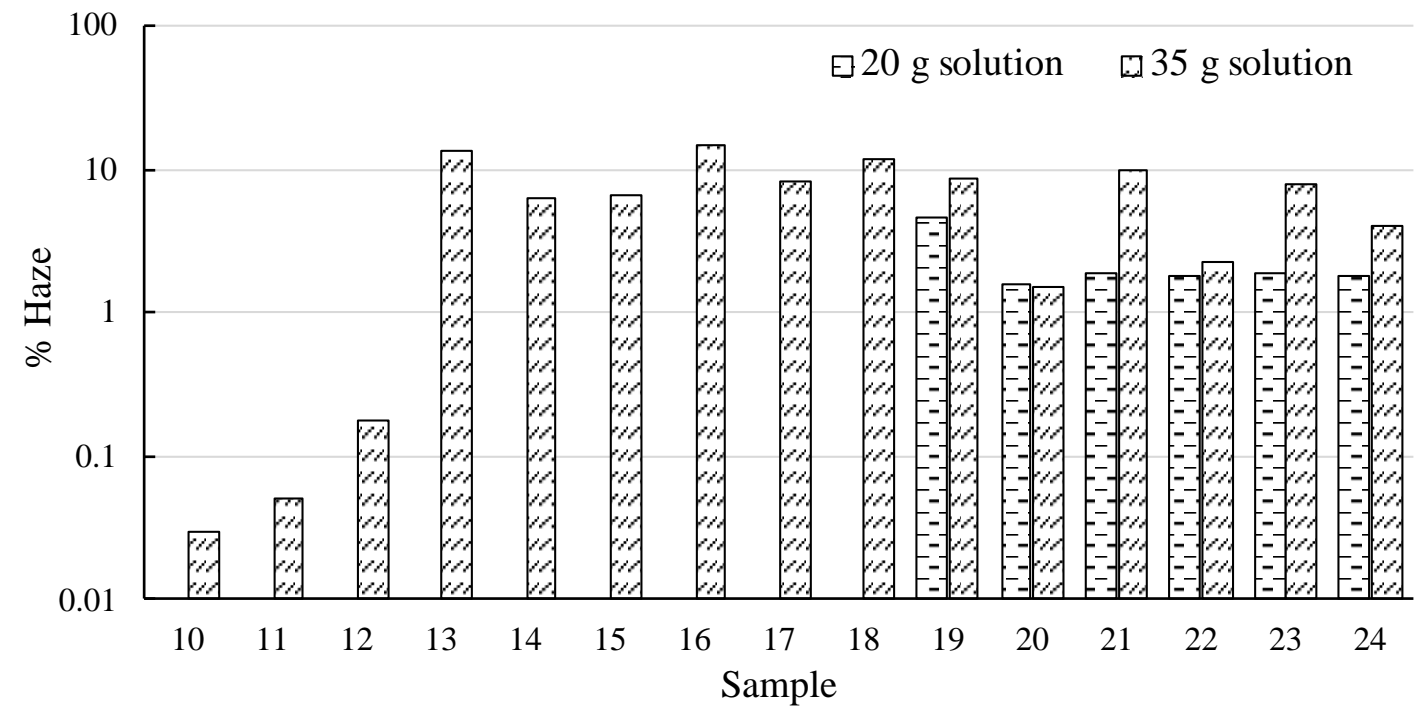

Figure 5. \% haze of the hydrogel films for Samples 10-24 for the 20 and $35 \mathrm{~g}$ casting solution

\section{Mechanical Properties}

Figure 6 illustrates the tensile strength and \%elongation of the films. As expected, these two properties have opposing trends. Strong materials usually exhibit high tensile strengths but low elasticities. As glycerol, which is a plasticizer, increased from $2.5 \% \mathrm{w} / \mathrm{v}$ in samples $10-12$ to $5 \% \mathrm{w} / \mathrm{v}$ in samples $13-15$ and to $7.5 \% \mathrm{w} / \mathrm{v}$ in samples $16-18$, the tensile strength decreased while the \%elongation increased. ANOVA testing at a significance level of $\alpha=0.05$ indicated that all chemicals, i.e. glycerol, PVA, and PS80, had significant 
effects on the tensile strength of the films as P-values of glycerol and PS80 are 0.000 and that of PVA is 0.005 . Figure 7 depicts a contour plot of the chemical compositions dependency on tensile strength for the hydrogel films. The plot shows that as the amount of glycerol increased, the tensile decreased monotonically. This is due to the fact that glycerol acts as a plasticizer for chitosan and PVA molecules. Similarly, as PVA concentration increased, the tensile strength slightly decreased as PVA provides the elasticity to the chitosan films and hence reduces the film's strength $[8,9]$. However, for PS80, it was found that as the PS80 concentration increased from $0-0.6 \% \mathrm{w} / \mathrm{v}$, the tensile strength of the hydrogel films deteriorated. At the PS80 concentration above 0.64 up to $1 \% \mathrm{w} / \mathrm{v}$, the tensile strength was improved. Therefore, the minimum PS80 concentration for this hydrogel should be at least $0.64 \% \mathrm{w} / \mathrm{v}$. According to the F-values, glycerol (Fvalue $=78.36)$ had the greatest effect whereas PVA $(F$-value $=11.62)$ had the least effect on tensile strength. Although the tensile strengths of these hydrogel films are considerably lowered than those prepared by chemical crosslinking or those of composite hydrogels [8, $9,11,12]$, they are close to chitosan/collagen hydrogel prepared by physical crosslinking [20]. It was found that introduction of collagen into chitosan hydrogel reduced the mechanical properties by half.

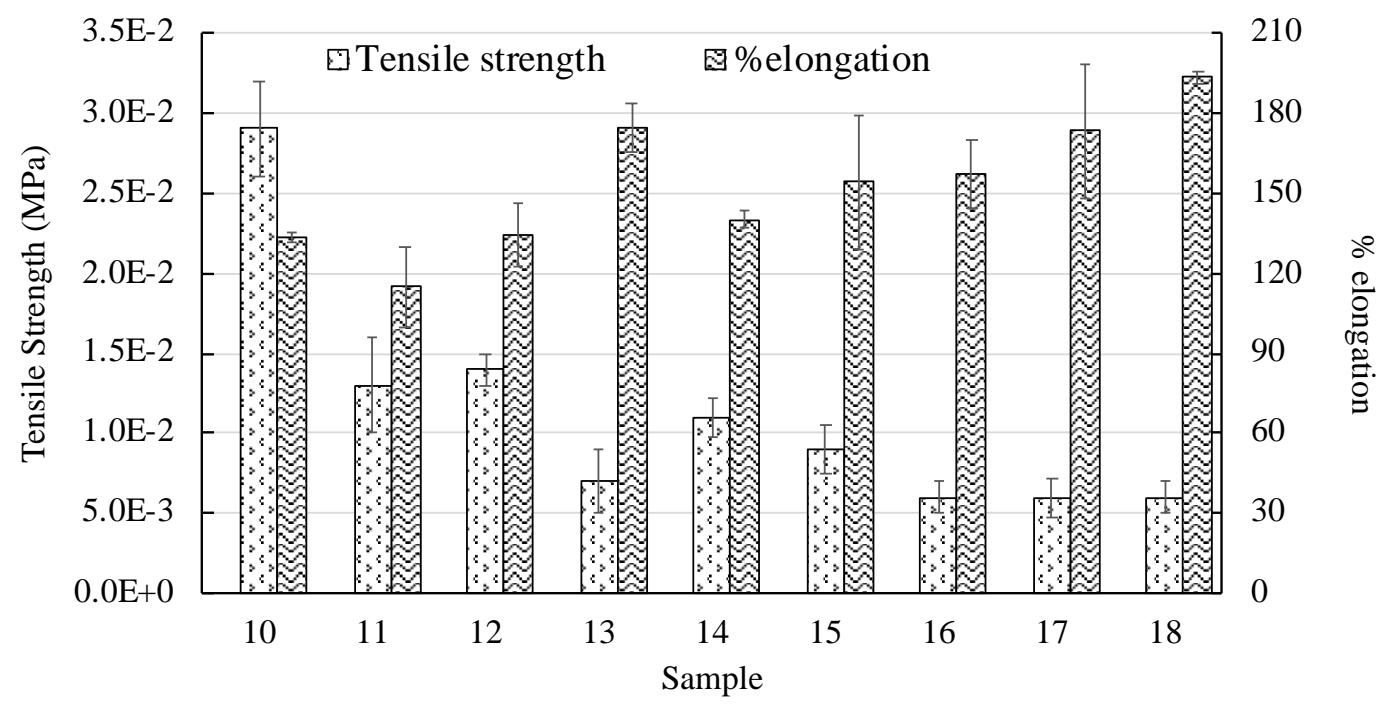

Figure 6. Mechanical properties of Samples 10-18 hydrogel films

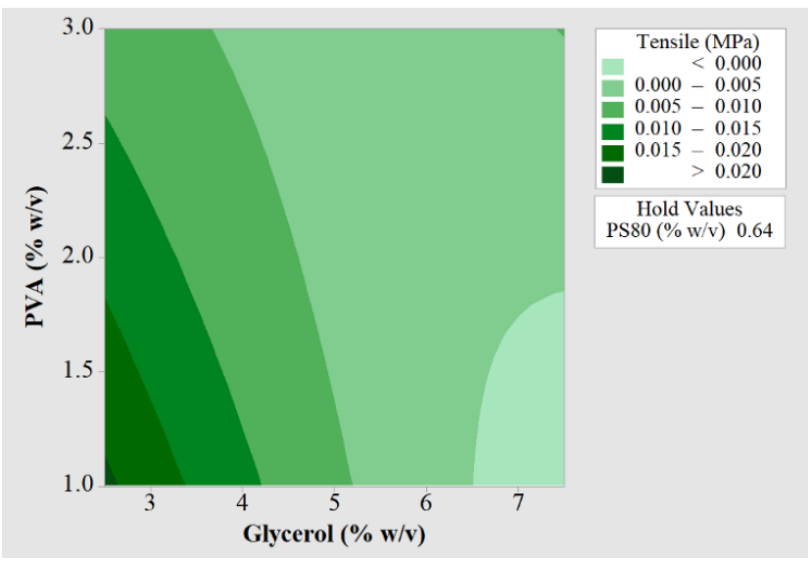

(a)

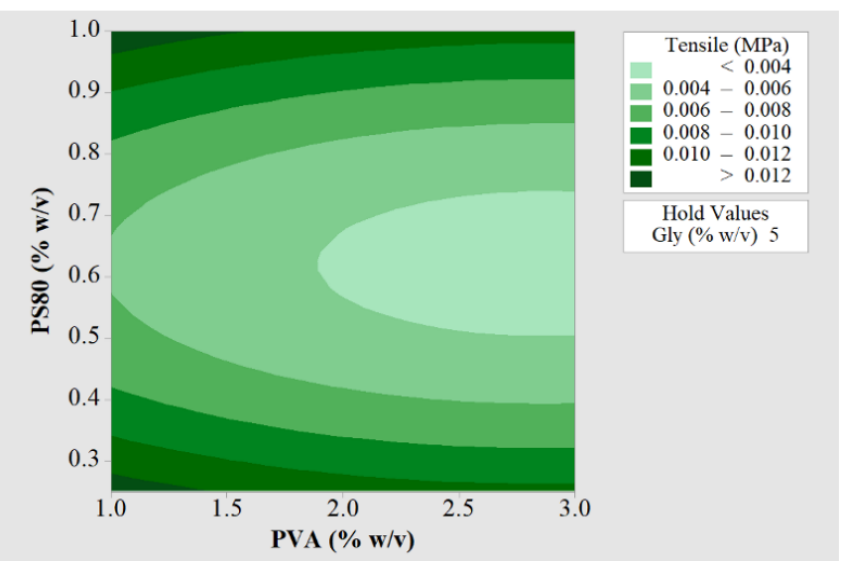

(b)

Figure 7. Contour plots of tensile strength (a) PVA and glycerol at different concentration at $0.64 \% \mathrm{w} / \mathrm{v}$ PS80 (b) PVA and PS80 at different concentration at 5\% w/v glycerol 
Figure 8 and 9 revealed that film thickness of the hydrogel had an effect on both tensile strength and \%elongation. Although it is known that tensile strength, which is a total force required for failure per unit cross-sectional area of the sample, is an intrinsic property and independent of the sample thickness, however, it is usually found that material thickness can influence this property. This is usually due to the microstructure of the materials such as porosity, flaws, and other defects. Hydrogels prepared in our study were moderately in high viscosity and hence, air trapped within the film could easily occur. The results showed that as the thickness of the hydrogel increased 1.8 times, the tensile strength increased approximately 1-2 times whilst the \%elongation increased 1.5 times. In addition to the influences of the film thickness on the mechanical properties, the \%swelling of the film (data not included) also slightly increased by $20-30 \%$ as the films were 1.8 times thicker. One of the factors influencing water absorption or the swelling of hydrogels is the elasticity of the polymer chains. The increase in water absorption of the thicker films might be due to the higher elasticity observed from an increase in \%elongation. The films with higher elasticity of the polymer chains has lower resistance to water absorption, resulting in high \%swelling.

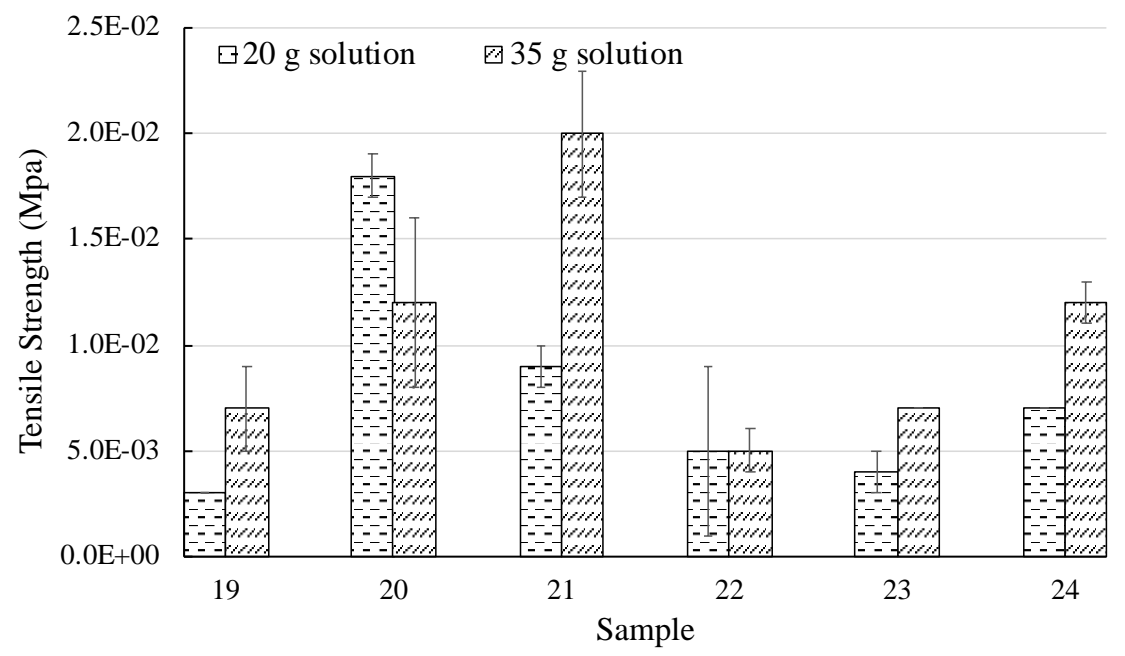

Figure 8. Tensile strength of Samples 19-24 hydrogels at different thickness

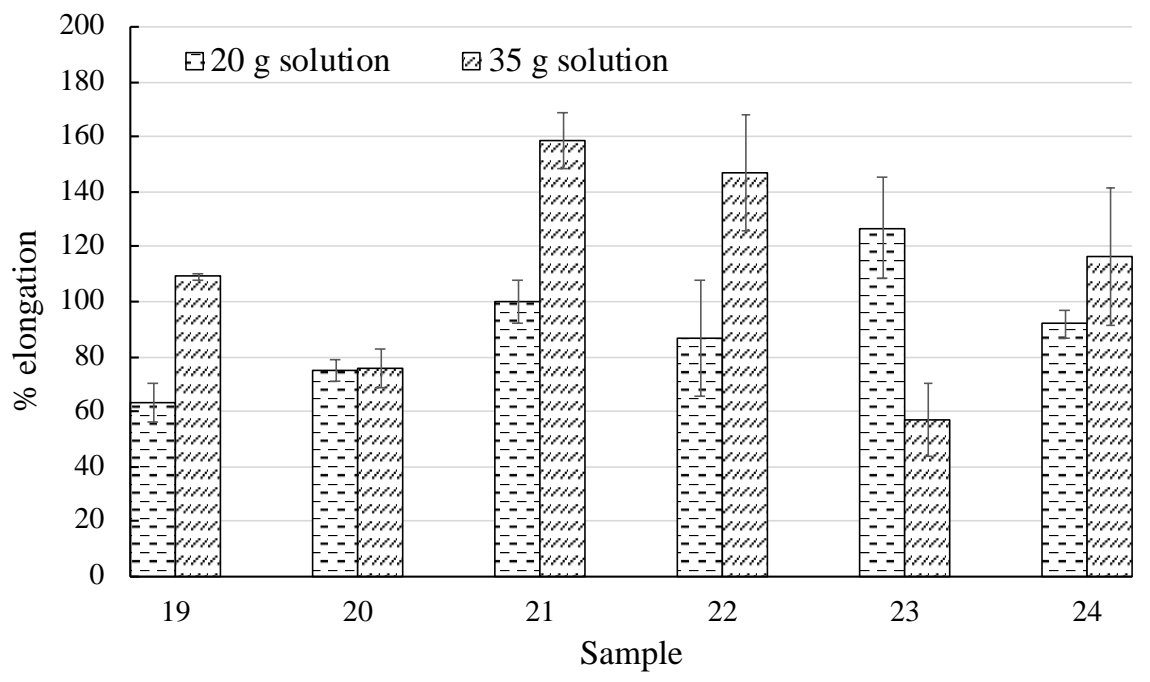

Figure 9. \%elongation of Samples 19-24 hydrogels at different thickness 


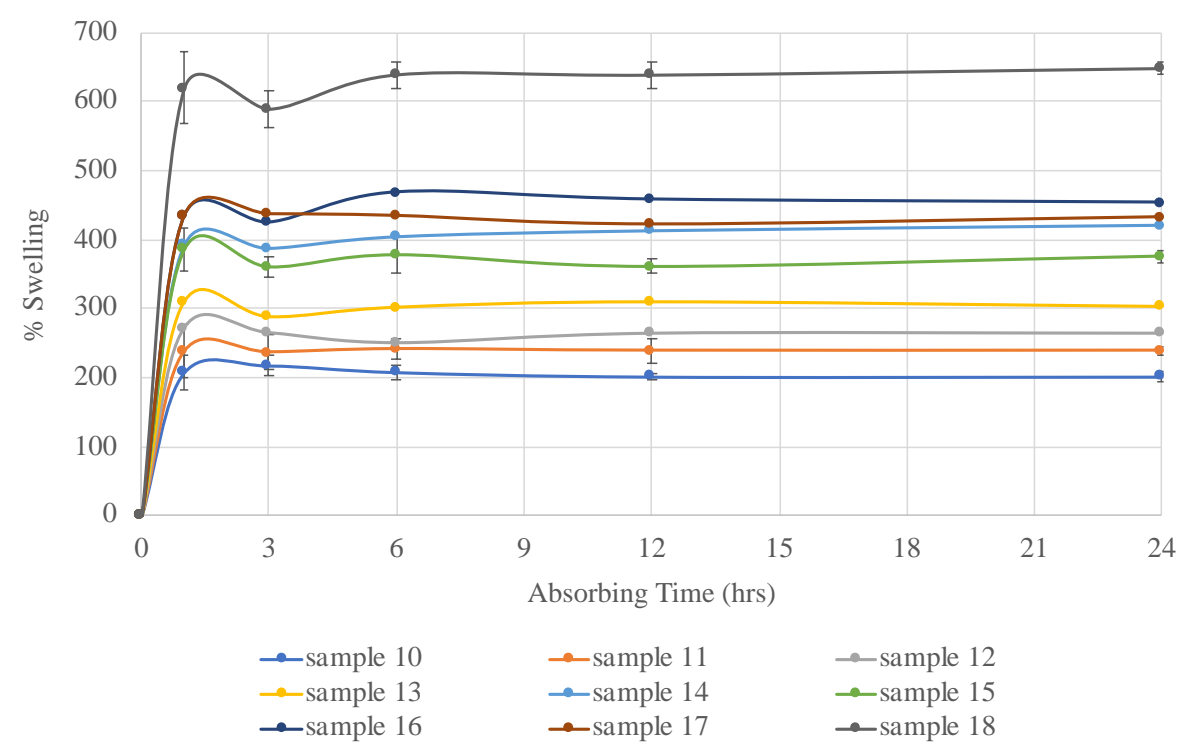

Figure 10. Swelling behaviour of Samples 10-18 hydrogel films

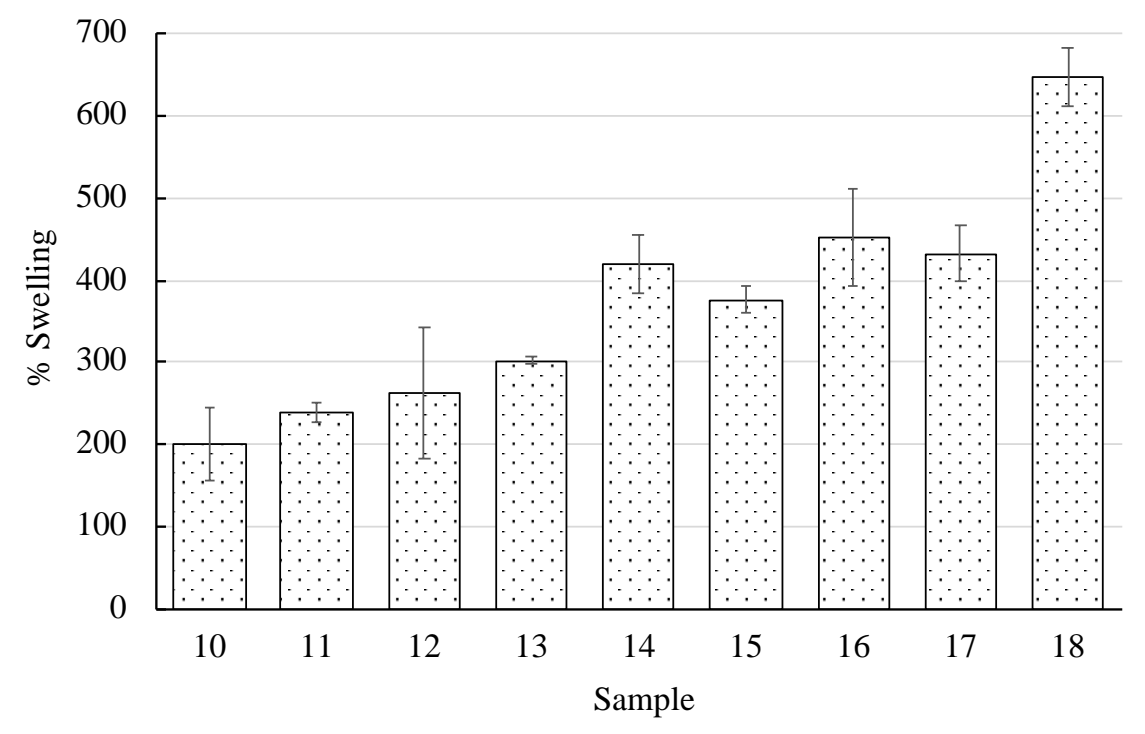

Figure 11. \% swelling of Samples 10-18 hydrogel films

\section{\%Swelling}

Figure 10 presents the swelling behavior with time of hydrogel samples $10-18$. The results show that the films absorb water rapidly within the first hour. At 3 hrs however, the film weight decreased slightly before increasing again and reaching a plateau after roughly 6 hrs. The initial high absorption rate may be due to the initial absence of water in the film which promotes a high driving force for water transfer into the film as observed by the steep rise in $\%$ swelling and slight overshoot. Once there was water in the films, the driving force dramatically decreased and the excess water was desorbed to provide a balance between chemical potentials inside and outside the films. The observed swelling behavior of the hydrogel is similar to those observed by other researchers, but the equilibrium time and percent water absorbed depended on each film type [5, 9-13, 20]. As the glycerol contents increased from $2.5,5.0$, and $7.5 \% \mathrm{w} / \mathrm{v}$, the film swelling also considerably increased 200 $260 \%, 300-420 \%$, and $430-650 \%$, respectively. This might be attributable to the $\mathrm{OH}$ groups 
of the glycerol as well as the looser structure of the films with a high plasticizer content. Conversely, PVA and PS80 had minimal effects on the swelling ratio. The swelling behavior of hydrogels is related to its degree of crosslinking and hence affects its mechanical properties. The hydrogel film with a high crosslink density possesses less voids for absorbing water and liquid. On the other hand, the high crosslink density improves mechanical properties. The swelling trend of these hydrogel films followed the hypothesis. As the tensile strength of the film decreased as seen in Figure 6, the swelling ratio of the films improved as shown in Figure 11. The maximum \%swelling of these hydrogel films tested achieved approximately $650 \%$.

\section{Collagen Absorption and Release}

Collagen absorption was performed using a direct addition technique where the hydrogel films were soaked in a $15 \% \mathrm{w} / \mathrm{v}$ collagen solution for $24 \mathrm{hrs}$ and the absorbed collagen was determined. Figure 12 shows that the films absorbed collagen solution in the range of 3$4.3 \% \mathrm{w} / \mathrm{v}$, equivalent to $20-30 \%$ absorption. ANOVA demonstrated that both PVA and glycerol (P-value $=0.000$ for both) have significant effects on the collagen absorption whereas PS80 (P-value $=0.362)$ did not have any influence (data not shown here). In addition, the higher F-value of PVA (344.97) than that of glycerol (112.71) suggested PVA had a stronger effect. The surface response plot indicates that the collagen absorption improved proportionally to the amount of glycerol but inversely proportional to the PVA content. Although both glycerol and PVA contains a large amount of OH groups, PVA has significantly larger molecules than glycerol and this could threaten the bonding with $\mathrm{H}$ molecules in collagen. The effects of initial collagen concentrations as well as the hydrogel film thickness on the collagen absorption were also studied. Two initial collagen concentrations of 15 and $30 \% \mathrm{w} / \mathrm{v}$ were loaded onto two different hydrogel film thickness and the absorption results are shown in Figures 13 and 14, respectively. Interestingly, absorption capability was found to be independent of the film thickness at both initial concentrations even though it was shown that the thicker films had 30\% swelling higher than the thinner films. With the $15 \% \mathrm{w} / \mathrm{v}$ collagen solution, the collagen absorbed ranged between $4-5 \% \mathrm{w} / \mathrm{v}$, equivalent to $30 \%$ absorption. When the initial collagen concentration was doubled $(30 \% \mathrm{w} / \mathrm{v})$, the collagen absorption increased doubled as $(7.5-9.5 \%)$; however, this was still equivalent to $30 \%$ absorption of the initial solution.

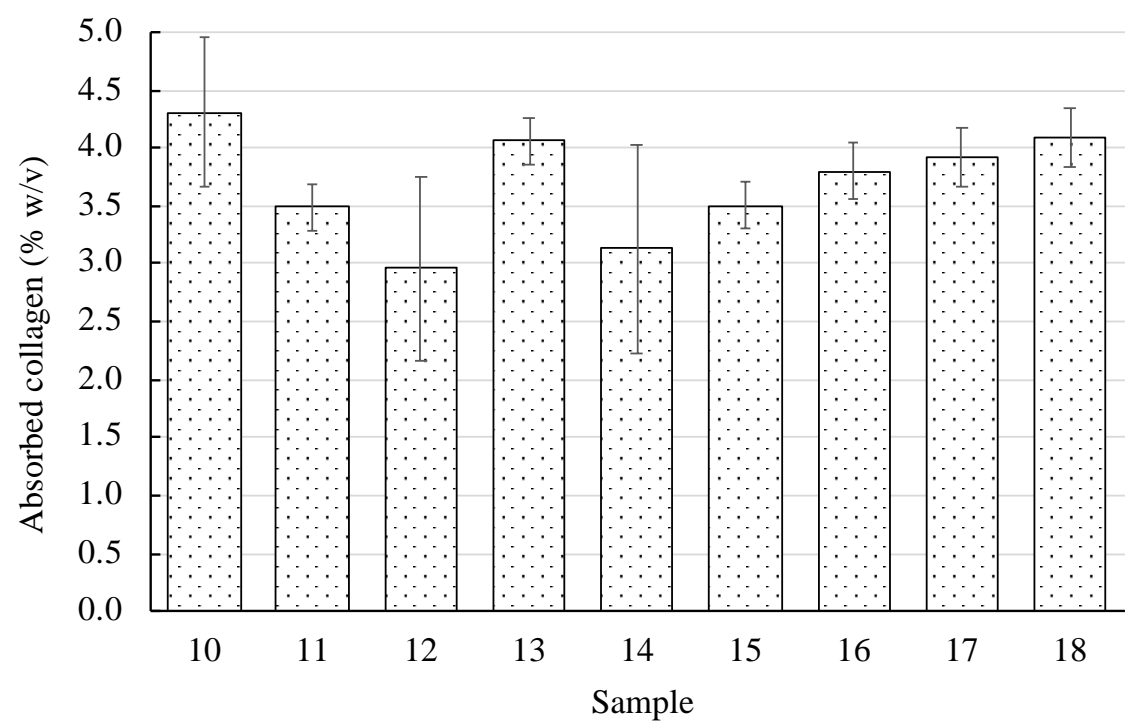

Figure 12. Collagen absorption of hydrogel samples $10-18$ with the initial $15 \% \mathrm{w} / \mathrm{v}$ collagen solution 


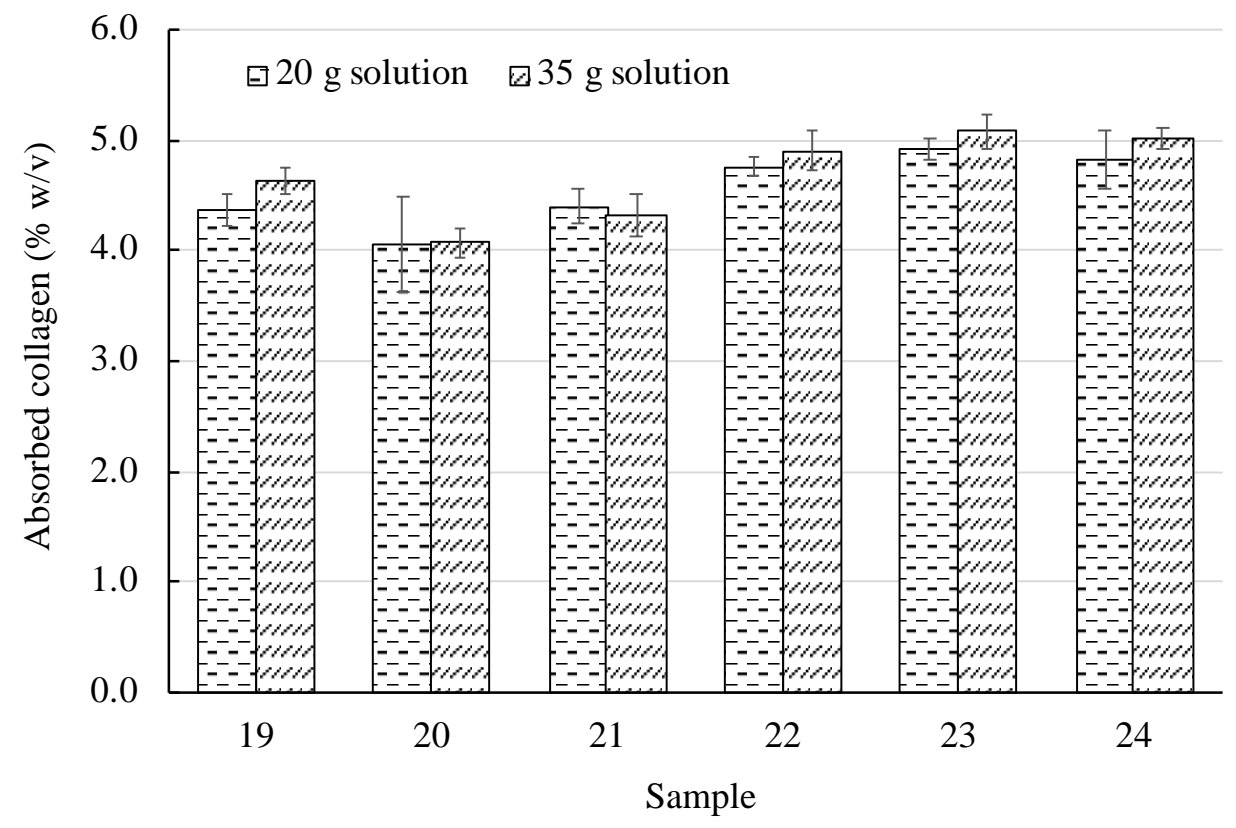

Figure 13. Collagen absorption of hydrogel with different film thickness at the initial $15 \%$ w/v collagen solution

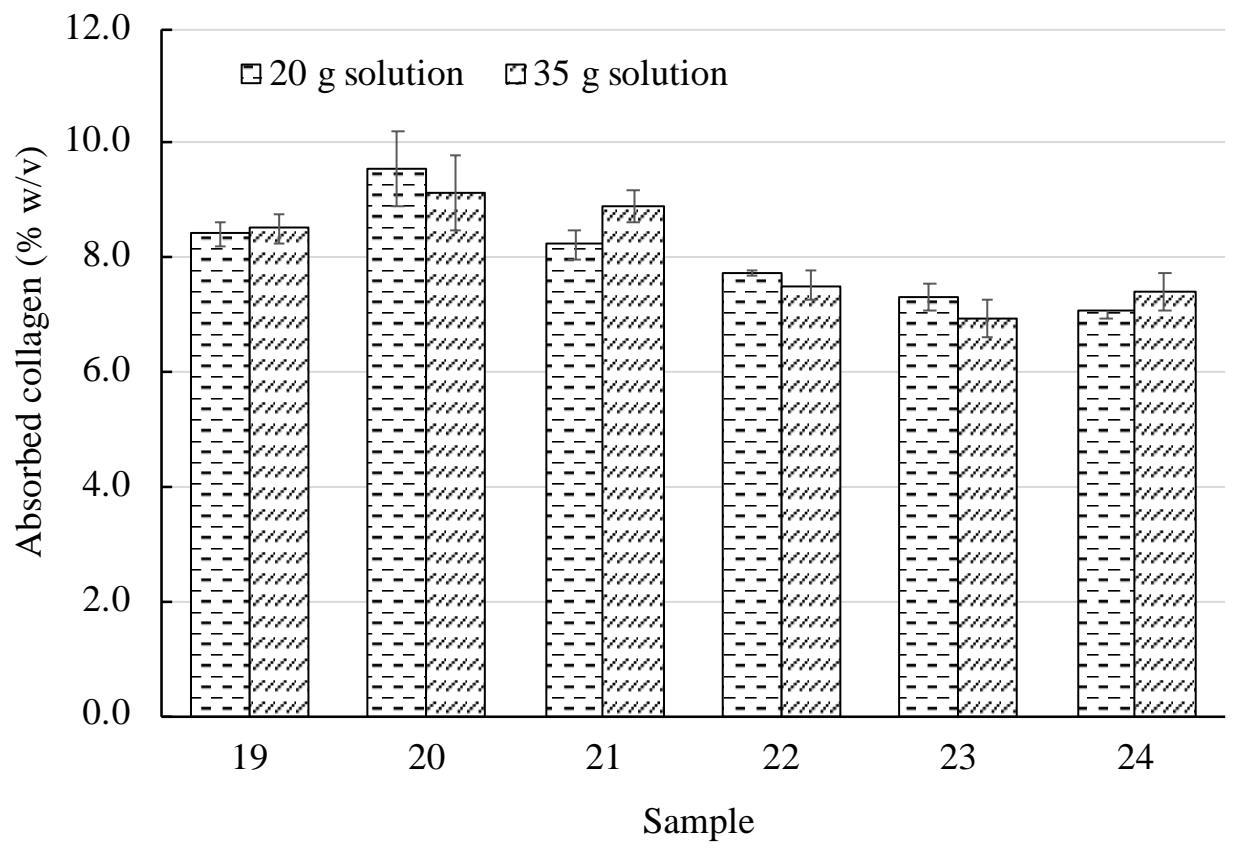

Figure 14. Collagen absorption of hydrogel with different film thickness at the initial $30 \%$ $\mathrm{w} / \mathrm{v}$ collagen solution

Collagen release or desorption was performed using PBS to imitate human skin. The release of collagen was very fast and within $3 \mathrm{hrs}$ the collagen desorption was almost complete for most hydrogel films as shown in Figure 15. The quick release might be due to the weak interaction forces between collagen and the hydrogel which were physically incorporated. The collagen release could occur by diffusion and swelling of the hydrogel. The results of ANOVA at a significance level of $\alpha=0.05$ indicated that only PVA and PS80 
had a significant effect on the release of the collagen with the P-values of 0.000 and 0.001 , respectively. Comparing the F-values of the two compositions, it was demonstrated that both had the same degree of influence on the collagen release (F-values of 19.39 and 17.25). The contour plot suggests that the optimum compositions for the most effective collagen release was at the amount of PVA content of approximately $2 \% \mathrm{w} / \mathrm{v}$ and of PS 80 content of either 0 or $1 \% \mathrm{w} / \mathrm{v}$. Although the results from collagen absorption displayed that the film thickness did not have any effect on the absorption capacity, Figures 16 and 17 clearly show that the thicker films release collagen more effective at both initial collagen concentrations of 15 and $30 \% \mathrm{w} / \mathrm{v}$, respectively. Nevertheless, the complete collagen release was eventually achieved for all the films. Considering the hydrogel film thickness, the results indicate that it had effects on mechanical properties, \%swelling, and collagen release rate, but not the \% collagen absorption. Additionally, it was found that the films with different chemical compositions in the range of this study could absorb collagen at around $30 \% \mathrm{w} / \mathrm{v}$, regardless of the initial collagen concentration and film thickness. This might be due to the limited polarity of the chitosan-PVA-collagen.

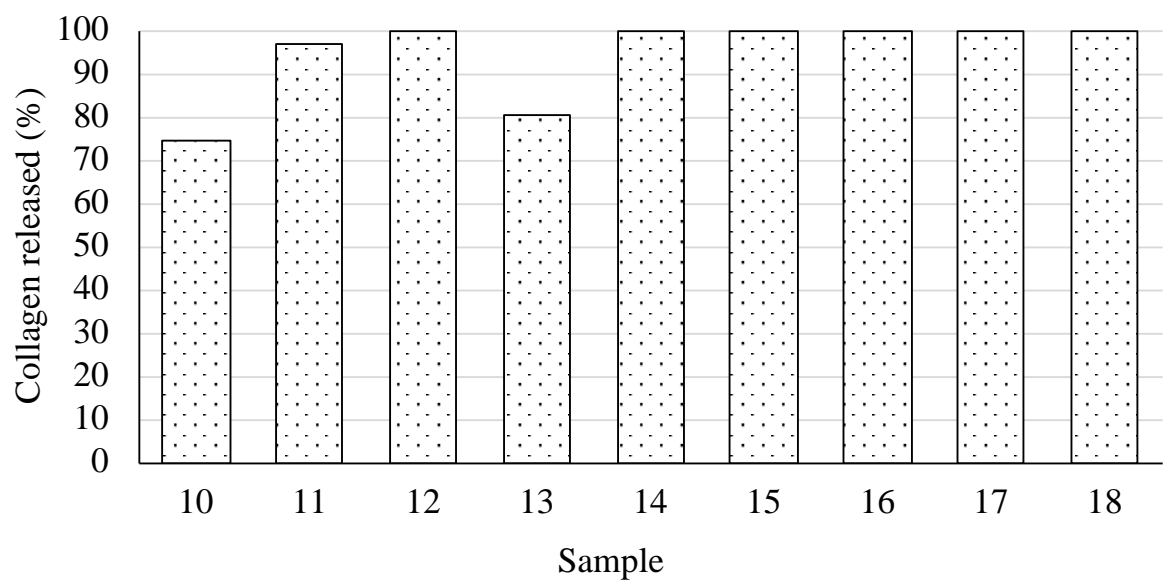

Figure 15. Collagen release of hydrogel of samples 10-18 at $3 \mathrm{hrs}$

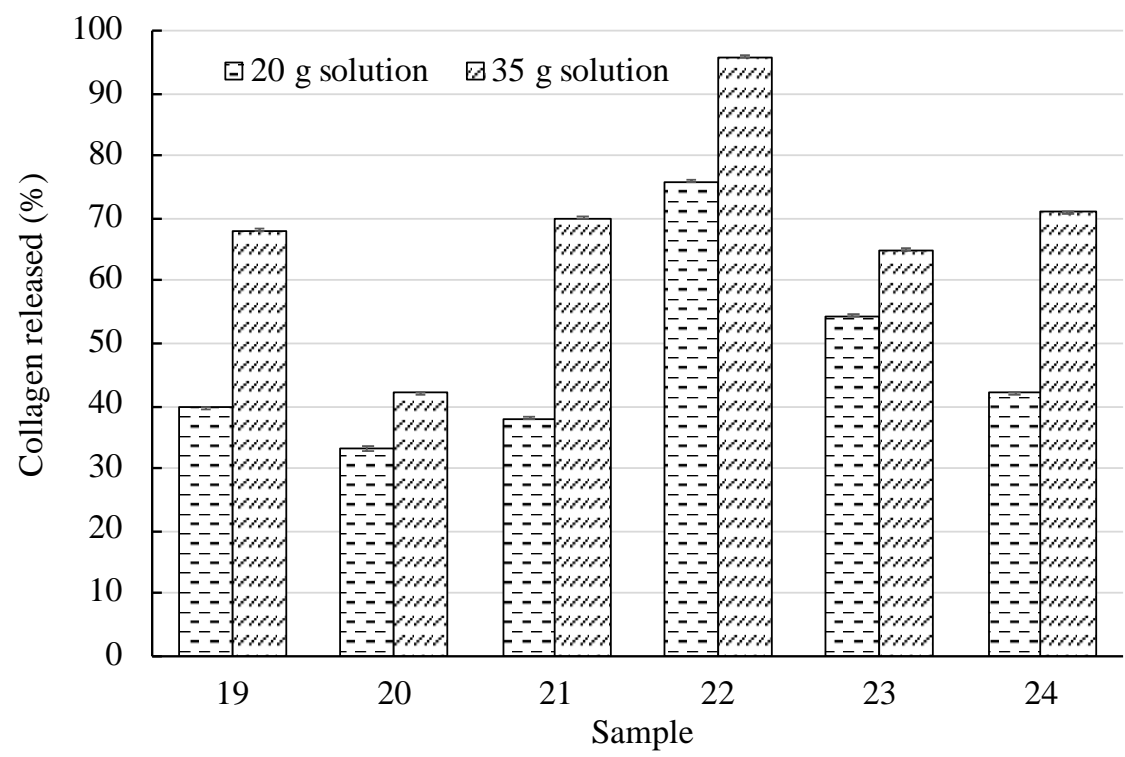

Figure 16. Collagen release of hydrogels of different film thickness at $3 \mathrm{hrs}$ (the initial $15 \%$ $\mathrm{w} / \mathrm{v}$ collagen solution) 


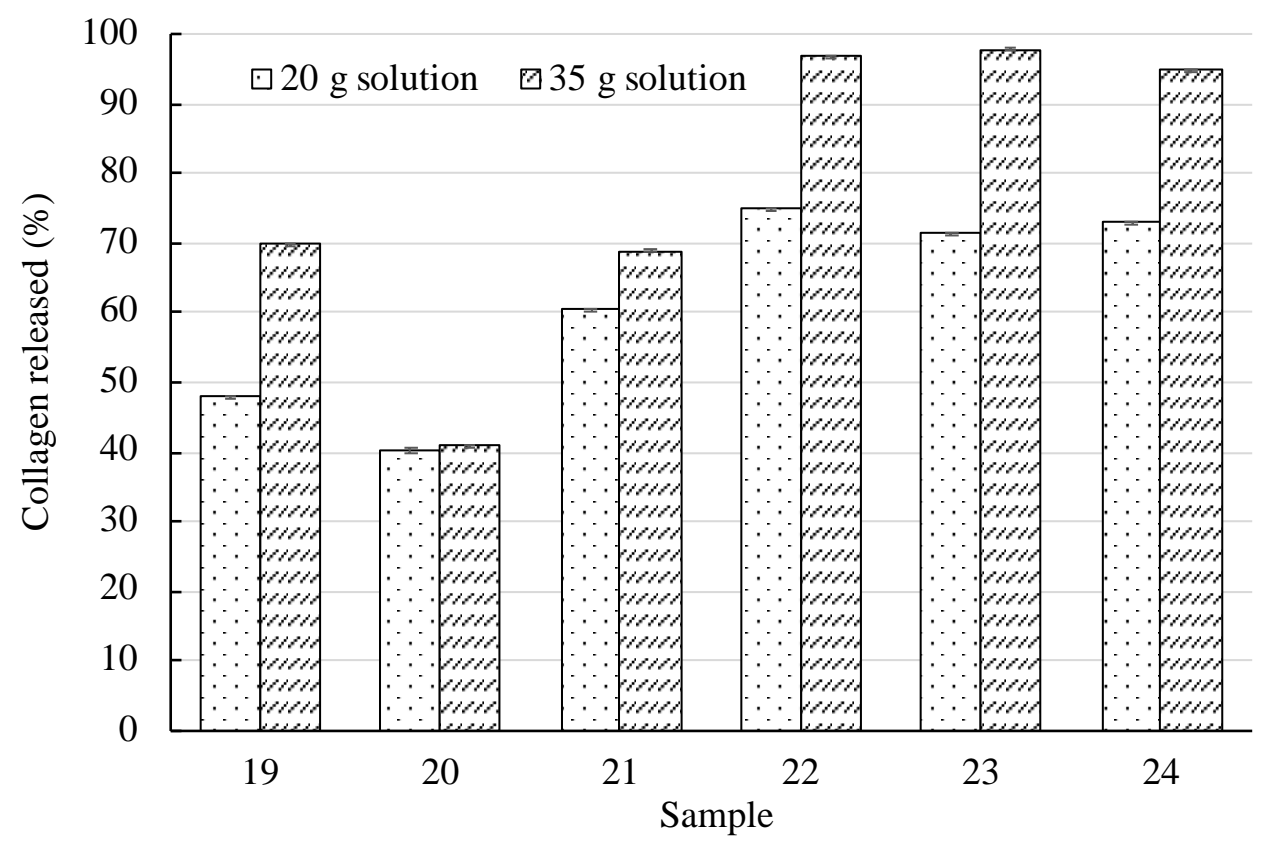

Figure 17. Collagen release of hydrogels of different film thickness at $3 \mathrm{hrs}$ (the initial $30 \%$ w/v collagen solution)

\section{Conclusions}

This study investigated the effects of chemical compositions on the properties of the hydrogel films. Ethanol was included into the hydrogel compositions as it has a high vapor pressure and hence was expected to accelerate the film drying. However, the results reveal that it did not have any influences in the film drying. PS80 which is an emulsifier was also included in the hydrogel compositions with an expectation that the films properties would be enhanced due to a better homogeneity. However, it did not show any significant effects either except in the hydrogels mechanical properties. On the other hand, glycerol which is a plasticizer, and PVA which is a co-hydrogel film base, demonstrated that it has a significant effect on several of the film's properties including drying time, \%haze, mechanical properties, and collagen absorption and release. As the amount of glycerol increased, the elasticity of the film increased while the strength of the film decreased. The percent swelling also increased with increasing glycerol content. For PVA, it was found that an increase in its content increased the film elasticity. This might be due to having a less complex molecular structure than chitosan. Interestingly, it was observed that the collagen absorption was independent of the hydrogel compositions as well as film thickness. The maximum collagen absorption was found to be approximately $30 \% \mathrm{w} / \mathrm{v}$. As the collagen and hydrogel were physically incorporated, the interactions between the two components were weak and hence the collagen release was easy and complete. The collagen release was more effective with the thicker film as the thicker film demonstrated higher percent swelling. It is recommended that further study investigating the microstructure of the hydrogel films is undertaken to gain more support and understanding of these findings.

\section{Acknowledgement}

This work was financially supported by the Research Grant of Burapha University through the National Research Council of Thailand (Grant no. 26/2561). 


\section{References}

[1] J. Maitra, and V.K. Shykla, "Cross-linking in hydrogels - A review," American Journal of Polymer Science, Vol 4, No. 2, pp. 25-31, 2014.

[2] A. Mignon, N. De Belie, P. Dubruel, and S. Van Vlierberghe, "Superabsorbent polymers: A review on the characteristics and applications of synthetic, polysaccharide-based, semi-synthetic and 'smart' derivatives," European Polymer Journal, Vol. 117, pp. 165$178,2019$.

[3] E. Kamoun, El-R. Kenawy, and X. Chen, "A review on polymeric hydrogel membranes for wound dressing applications: PVA-based hydrogel dressings," Journal of Advanced Research, Vol. 8, No. 3, pp. 217-233, 2017.

[4] K. Kolan, Y. Liu, J. Baldridge, C. Murphy, J. Semon, D. Day, and M. Leu, "Solvent based 3D printing of biopolymer/bioactive glass composite and hydrogel for tissue engineering applications," Procedia CIRP, Vol. 65, pp. 38-43, 2017.

[5] Y. Zhang, M. Jiang, Y. Zhang, Q. Cao, X. Wang, Y. Han, G. Sun, Y. Li, and J. Zhou, "Novel lignin-chitosan-PVA composite hydrogel for wound dressing," Materials Science and Engineering C, Materials for Biological Applications, Vol. 104:110002, 2019. doi: 10.1016/j.msec.2019.110002

[6] F. Yang, W. He, H. Li, X. Zhang, and Y. Feng, "Role of acid treatment combined with the use of urea in forming cellulose hydrogel," Carbohydrate Polymers, Vol. 223:115059, 2019. doi: 10.1016/j.carbpol.2019.115059

[7] B. Biduski, W.M.F.D. Silva, R. Colussi, S.L.M.E. Halal, L.T. Lim, A.R.G. Dias, E.D.R. Zavareze, "Starch hydrogels: The influence of the amylose content and gelatinization method," International Journal of Biological Macromolecules, Vol. 113, pp. 443-449, 2018. doi: 10.1016/j.ijbiomac.2018.02.144

[8] J. Bonilla, E. Fortunati, L. Atarés, A. Chiralt, and J.M. Kenny, "Physical, structural and antimicrobial properties of poly vinyl alcohol-chitosan biodegradable films," Food Hydrocolloids, Vol. 35, pp. 463-470, 2014.

[9] K. Vimala, Y. Mohan, K. Varaprasad, N.N. Reddy, S. Ravindra, N.S. Naidu, and K.M. Raju, "Fabrication of curcumin encapsulated chitosan-PVA silver nanocomposite films for improved antimicrobial activity," Journal of Biomaterials and Nanobiotechnology, Vol. 2, pp. 55-64, 2011. doi: 10.4236/jbnb.2011.21008

[10] W. Yang, E. Fortunati, F. Bertoglio, J.S. Owczarek, G. Bruni, M. Kozanecki, J.M. Kenny, L. Torre, L. Visai, and D. Puglia, "Polyvinyl alcohol/chitosan hydrogels with enhanced antioxidant and antibacterial properties induced by lignin nanoparticles," Carbohydrate Polymers, Vol. 181, pp. 275-284, 2018. doi: 10.1016/j.carbpol.2017.10.084

[11] L. Fan, H. Yang, J. Yang, M. Peng, and J. Hu, "Preparation and characterization of chitosan/gelatin/PVA hydrogel for wound dressings," Carbohydrate Polymers, Vol. 146, pp. 427-434, 2016. doi: 10.1016/j.carbpol.2016.03.002

[12] V.L. Peña-Reyes, M.Q. Marin-Bustamante, A. Manzo-Robledo, J.J. Chanona-Pérez, R.G. Cásarez-Santiago, and E. Suarez-Najera, "Effect of crosslinking of alginate/pva and chitosan/pva, reinforced with cellulose nanoparticles obtained from agave Atrovirens karw," Procedia Engineering, Vol. 200, pp. 434-439, 2017.

[13] R. Liu, X. Xu, X. Zhuang, and B. Cheng, "Solution blowing of chitosan/PVA hydrogel nanofiber mats," Carbohydrate Polymers, Vol. 101, No. 1, pp. 1116-1121, 2014.

[14] K. Thinkohkaewa, N. Rodthongkumb, and S. Ummartyotin, "Coconut husk (Cocos nucifera) cellulose reinforced poly vinyl alcohol-based hydrogel composite with controlrelease behavior of methylene blue," Journal of Materials Research and Technology, Vol. 9, No. 3, pp. 6602-6611, 2020. doi: 10.1016/j.jmrt.2020.04.051 
[15] P. Gami, D. Kundu, S.D.K. Seera, and T. Banerjee, "Chemically crosslinked xylan- $\beta-$ Cyclodextrin hydrogel for the in vitro delivery of curcumin and 5-Fluorouracil," International Journal of Biological Macromolecules, Vol. 158, pp. 18-31, 2020. doi: 10.1016/j.ijbiomac.2020.04.237

[16] R. Nakata, Y. Osumi, S. Miyagawa, A. Tachibana, and T. Tanabe, "Preparation of keratin and chemically modified keratin hydrogels and their evaluation as cell substrate with drug releasing ability," Journal of Bioscience and Bioengineering, Vol. 120, No. 1, pp. 111-116, 2015. doi: 10.1016/j.jbiosc.2014.12.005

[17] J. Nath, A. Ahmed, P. Saikia, A. Chowdhury, S.K. Dolui, "Acrylic acid grafted gelatin/LDH based biocompatible hydrogel with $\mathrm{pH}-\mathrm{T}$ controllable release of vitamin B12," Applied Clay Science, Vol. 190, pp. 105569-105578, 2020. doi: 10.1016/j.clay.2020.105569

[18] T. Lee and H.Y. Chang, "Structural, physicochemical, and in-vitro release properties of hydrogel beads produced by oligochitosan and de-esterified pectin from yuzu (Citrus junos) peel as a quercetin delivery system for colon target," Food Hydrocolloids, Vol.108, pp. 106086-106097, 2020. doi: 10.1016/j.foodhyd.2020.106086

[19] S. Upasen, K. Naermitmarnsuk, C. Antonio, S. Roces, H. Morillas, and P. Wattanachai, "Acid-pepsin soluble collagen from saltwater and freshwater fish scales," Engineering Journal, Vol. 23, No. 5, pp. 183-195, 2019. doi:10.4186/ej.2019.23.5.183

[20] S. Mousavi, A.B. Khoshfetrat, N. Khatami, M. Ahmadian, and R. Rahbarghazi, "Comparative study of collagen and gelatin in chitosan-based hydrogels for effective wound dressing: Physical properties and fibroblastic cell behavior," Biochemical and Biophysical Research Communications, Vol. 518, No. 4, pp. 625-631, 2019. doi: 10.1016/j.bbrc.2019.08.102

[21] A.L. Skwarczynska, D. Binias, W. Maniukiewicz, Z. Modrzejewska, and T. Douglas, "The mineralization effect on chitosan hydrogel structure containing collagen and alkaline phosphatase," Journal of Molecular Structure, Vol. 1187, pp. 86-97, 2019. 